Document downloaded from:

http://hdl.handle.net/10251/43236

This paper must be cited as:

Vacas González, S.; Alfaro Cañamás, C.; Zarzo Castelló, M.; Navarro-Llopis, V.; Primo Millo, J. (2011). Effect of sex pheromone emission on the attraction of Lobesia botrana. Entomologia Experimentalis et Applicata. 139(3):250-257. doi:10.1111/j.15707458.2011.01124.x.

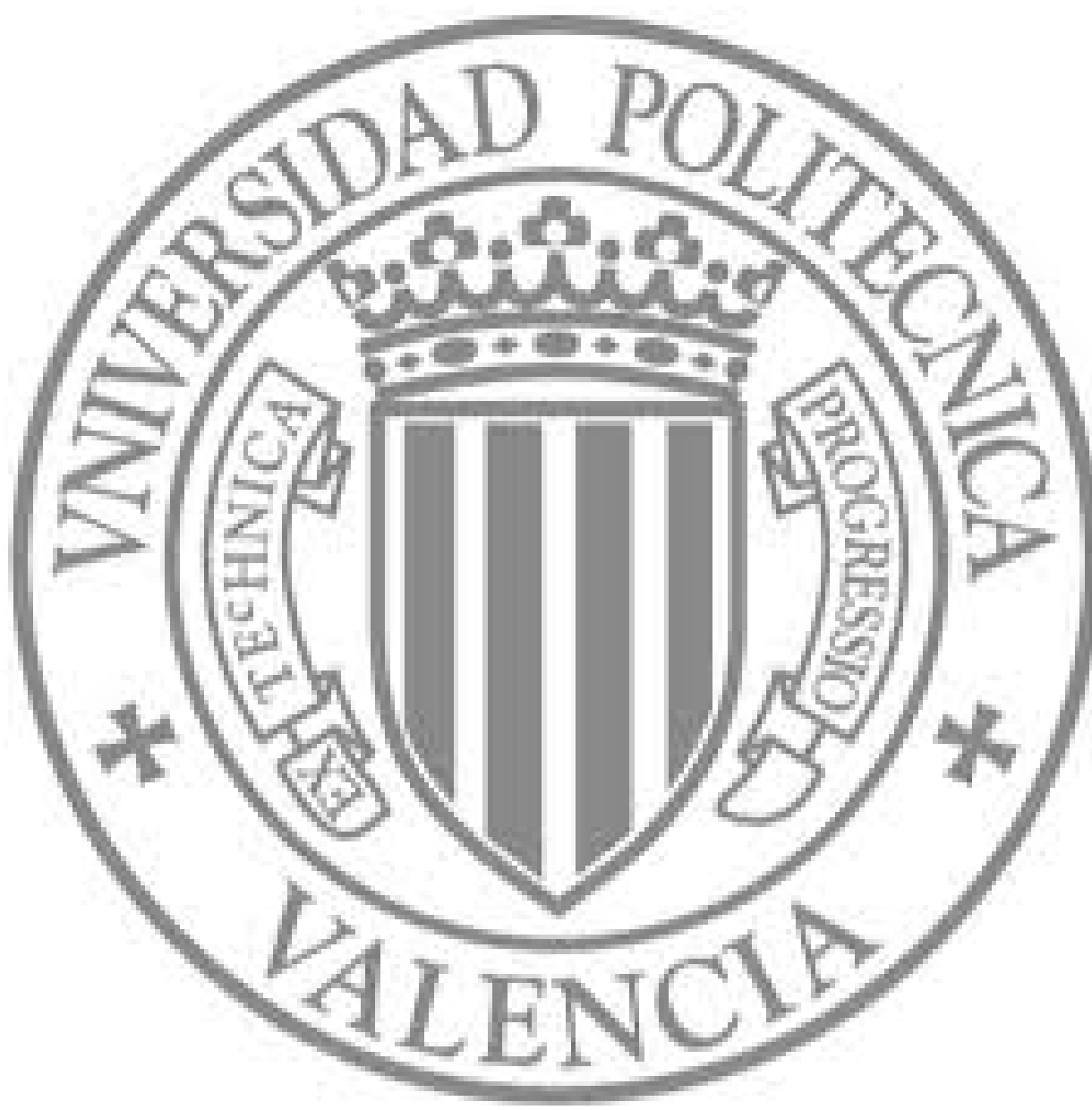

The final publication is available at

http://dx.doi.org/10.1111/j.1570-7458.2011.01124.x

Copyright Wiley 


\section{Effect of sex pheromone emission on the attraction of Lobesia}

\section{2 botrana}

3

4 Sandra $\operatorname{Vacas}^{1}$, Cristina Alfaro ${ }^{1}$, Manuel $\mathrm{Zarzo}^{2}$, Vicente Navarro-Llopis ${ }^{1}$ \& Jaime

5 Primo 1

6

$7{ }^{1}$ Centro de Ecología Química Agrícola, Universidad Politécnica de Valencia, Edificio 6C, $5^{\text {a }}$

8 Planta, Camino de Vera s/n. 46022, Valencia, Spain, and ${ }^{2}$ Departamento de Estadística e

9 Investigación Operativa Aplicadas y Calidad, Universidad Politécnica de Valencia, Edificio

$10 \quad 7^{\mathrm{a}}$, Camino de Vera s/n. 46022, Valencia, Spain

11

12 *Correspondence: Sandra Vacas, Centro de Ecología Química Agrícola. Universidad

13 Politécnica de Valencia. Edificio 6C. 5 Planta. Camino de Vera s/n. 46022. Valencia, Spain.

14 E-mail: sanvagon@ceqa.upv.es

15

16 Short title: Pheromone emission for Lobesia botrana attraction

17

18 Keywords: European grapevine moth, monitoring, mass trapping, attract and kill,

19 mesoporous dispenser, Lepidoptera, Tortricidae, release rate

20

21 Accepted: 12 April 2011

22

23 


\section{Abstract}

25 Since the discovery of Lobesia botrana Denis \& Schiffermüller (Lepidoptera: Tortricidae) sex

26 pheromone, it has played an important role in the control and detection of this pest, for

27 example, through the use of pheromone-baited traps and mating disruption techniques.

28 Rubber septa are the most common pheromone dispensers used in monitoring traps, but often

29 dispenser performance is not optimized. The key to improve methods based on pheromones as 30 attractants (monitoring, mass trapping, or 'attract and kill') is to know the optimum emission

31 interval, because release rates can strongly affect the attraction. In this work, five levels of

32 pheromone load with different release rates were compared in traps using mesoporous

33 pheromone dispensers to investigate the optimum release rate maximizing L. botrana catches.

34 Residual pheromone loads of the dispensers were extracted and quantified by gas

35 chromatography, in order to study release profiles and to estimate the various emission levels.

36 The efficacy of pheromone emission was measured in field trials as number of moths caught.

37 A quadratic model was fitted to relate the numbers caught vs. the daily emission rates. The

38 resulting quadratic term was statistically significant, confirming the existence of a relative

39 maximum for L. botrana catches. Taking into account that the trial was carried out only in

40 one location, an optimum emission value of ca. $400 \mu \mathrm{g}$ per day could be considered to

41 enhance the attraction of L. botrana under West-Mediterranean weather conditions. 
44 The European grapevine moth, Lobesia botrana Denis \& Schiffermüller (Lepidoptera: Tortricidae), is a key pest of grapes in Central Europe and most Mediterranean countries (Anshelevich et al., 1994). Pest damage is mainly caused by larvae feeding on grapes, which leads to fungal colonization of wounds and fruit rot. Traditional chemical control was the main tool to fight L. botrana, but since the identification of its sex pheromone in the 1970s (Roelofs et al., 1973), it has been widely used for almost 2 decades against this pest in Germany, Switzerland, and Northern Italy. In other European regions, however, the introduction of pheromone-based methods has been slower (Witzgall et al., 2010). Roelofs et al. (1973) described the main compound of L. botrana sex pheromone as (E,Z)-7,9dodecadienyl acetate. Two related compounds were identified later, $(E, Z)$-7,9-dodecadien-1ol and (Z)-9-dodecenyl acetate, having a synergistic effect on male catches (Arn et al., 1988; El-Sayed et al., 1999). These findings were crucial for the application of pheromone-based control and monitoring techniques. In fact, mating disruption is nowadays the most successful and widespread technique for controlling the moth in Europe. In addition, sex pheromonebaited traps were developed for monitoring $L$. botrana populations, playing an important role in pest detection and treatment timing. Rubber septa are the most common pheromone dispensers used in monitoring traps, but in most cases their performance is not optimized. A dispenser with an appropriate pheromone release rate is necessary to reach a good efficiency and to expand the use of pheromones in pest control systems.

The ideal dispenser should have a constant release rate during the whole flight period of the pest, independent of weather conditions (Jutsum \& Gordon, 1989; Leonhardt et al., 1989; Bradley et al., 1995). In order to improve control methods based on pheromones as attractants (monitoring, mass trapping, or 'attract and kill'), the key factor is to know the optimum emission interval, because release rates will strongly affect the attractiveness of the lure, and catches could decrease below and above this interval (Jacobson \& Beroza, 1964; Anshelevich et al., 1994; Zhang \& Amalin, 2005). There are some reports of responses of L. botrana to different pheromone loads of dispensers (Roehrich et al., 1983; Anshelevich et al., 1994). However, emission rates were not assessed, so trap catches were not correlated with emission values and optimal release rates were not proposed.

The goal of our study was to correlate field trap catches with different pheromone emission

74 values in order to study the optimum emission rate that maximizes the efficiency of the

75 attractant for the control of L. botrana. For this purpose, five levels of pheromone load with 76 different release rates of $(E, Z)$-7,9-dodecadienyl acetate (major active compound) were 
compared in traps using mesoporous pheromone dispensers. The efficiency of each emission level was measured in field trials as number of moths caught.

79

\section{Materials and methods}

\section{Pheromone dispensers and traps}

Three kinds of pheromone dispensers were employed for this trial. All of them were based on a mesoporous material (Corma et al., 1999, 2000), but they differed in size and pheromone load. Dispenser PD1 contained a pheromone load of $1 \mathrm{mg}$, and it was a cylindrical tablet, 9 $\mathrm{mm}$ in diameter and $3.5 \mathrm{~mm}$ high. The second (PD10) was loaded with $10 \mathrm{mg}$ of pheromone, and the tablet was $13 \mathrm{~mm}$ in diameter and $7.5 \mathrm{~mm}$ high. A third dispenser (PD30) was loaded with $30 \mathrm{mg}$ of pheromone, it was $13 \mathrm{~mm}$ in diameter and $20 \mathrm{~mm}$ high. (E,Z)-7,9-dodecadienyl acetate was used as the sex pheromone at $86 \%$ isomeric purity. The remaining $13 \%$ was the isomer (E,E)-7,9-dodecadienyl acetate, according to NMR analysis in our laboratory (data not shown). Previous work on L. botrana pheromone synthesis showed that the presence of the $(E, E)$-isomer in the blend did not interfere with the biological activity of the pheromone (Ideses et al., 1982). Pheromone was provided by Ecología y Protección Agrícola (Carlet, Spain) and dispensers were loaded with dichloromethane as solvent. For this trial, the mesoporous dispensers were manufactured by means of an industrial process that has around $15 \%$ of variability in the initial amount of pheromone (Ecología y Protección Agrícola).

Delta traps and sticky bases used in the field test were supplied by Biagro (Valencia, Spain). Each trap was baited with the corresponding pheromone dispensers, as described below.

\section{Field trial}

The field experiment was carried out from June to August 2009. The trial was designed as follows: four blocks of four traps were placed in a 4-ha Merlot vineyard, cultivated in trellis training. The orchard was in the centre of a 16-ha vineyard area located in Fontanars dels Alforins (Valencia, Spain); (Coordinates $\left.38^{\circ} 45^{\prime} \mathrm{N}, 0^{\circ} 50^{\prime} \mathrm{E}\right)$. Separation was $3 \mathrm{~m}$ between rows and $2 \mathrm{~m}$ between plants within each row. Distance between blocks was around $45 \mathrm{~m}$ and inter-trap distance was $50 \mathrm{~m}$. Traps at each block were baited with a different pheromone dose and will be referred to hereafter as PD1 (one PD1 dispenser), 3PD1 (three PD1dispensers), PD10 (one PD10 dispenser), and 3PD10 (three PD10 dispensers). Thus, their initial pheromone load was $1,3,10$, and $30 \mathrm{mg}$, respectively. All traps were hung at $1 \mathrm{~m}$ above the 
ground and their position inside each block was rotated weekly. None of these dispensers

111 were replaced during the test period. The traps were placed on 2 June 2009 and the moths caught were counted weekly during 2 months. According to the results of the first weeks, it was decided to include a higher additional emission level, referred to as 3PD30, so four replicates of the trap baited with three PD30 dispensers (i.e., initial pheromone load $90 \mathrm{mg}$ ) were placed in the field 1 month later (24 June). Weather parameters were obtained from the nearest meteorological station located in Montesa (Valencia, Spain), at $20 \mathrm{~km}$ from the

117 orchards.

\section{Pheromone emission rates}

120 During the trial, the three types of dispensers were aged in a vineyard located more than $2 \mathrm{~km}$ 121 from the catch traps. Dispensers were placed on 2 June inside delta traps for 96 days. At 122 different aging intervals a set of nine dispensers, three of each type, was taken to the 123 laboratory to be analyzed.

124 In order to determine daily emission rates, initial pheromone loads, and the residual 125 pheromone content of aged mesoporous dispensers were extracted in our laboratory by solvent extraction at $40{ }^{\circ} \mathrm{C}$ for $2 \mathrm{~h}$, using dichloromethane/methanol (2:3). The yield of all extractions was around $99 \%$.

128 Extracts were centrifuged at $3024 \mathrm{~g}$ for $8 \mathrm{~min}$. The supernates were quantified by gas 129 chromatography (GC) with flame ionization detector (GC/FID), using 1-dodecanol as internal 130 standard. For these analyses, a Clarus 500 gas chromatograph from Perkin Elmer (Wellesley, 131 MA, USA) was employed. All injections were made onto a ZB-5MS column $(30 \mathrm{~m} \times 0.25$ $132 \mathrm{~mm} \times 0.25 \mu \mathrm{m}$ ) that was held at $150^{\circ} \mathrm{C}$ for $3 \mathrm{~min}$ and programmed at $20^{\circ} \mathrm{C}$ per min to 170 $133{ }^{\circ} \mathrm{C}$, held at $170{ }^{\circ} \mathrm{C}$ for $4 \mathrm{~min}$, and then at $35^{\circ} \mathrm{C}$ per min to $260{ }^{\circ} \mathrm{C}$ for $2 \mathrm{~min}$. Helium was used 134 as carrier gas at $1.2 \mathrm{ml}$ per min with a split flow value of $30 \mathrm{ml}$ per min.

135 Retention time of the pheromone component was confirmed by GC/FID analysis of 136 commercial pheromone ( $86 \%$ isomeric purity; >99\% chemical purity), provided by Shin-Etsu 137 Chemical (Tokyo, Japan). The pheromone amount was calculated based on the ratio between 138 the peak areas of the pheromone component and 1-dodecanol, by means of a simple 139 regression model.

\section{Statistical analysis}

142 Our main goal was to study the pheromone emission effect on moth attraction and to 143 determine the optimum emission value. First, a multiple linear regression analysis was carried 
144 out to model the evolution of residual pheromone load vs. time for each type of dispenser.

145 The first derivative of the resulting equation provides an estimation of the daily emission rate.

146 Catch data were collected six times for 3PD30 traps and nine times for the others, once 147 every week, during the trial period. The $\sqrt{x}_{\mathrm{x}}$-transformation of the numbers caught was used to 148 normalize the data. Following the methodology applied in a previous study (Vacas et al., 149 2009), multiple linear regression (MLR) was used to relate catch data to the emission rate, 150 and to determine the relative maximum. The average number caught was highly variable from 151 week to week. Therefore, polynomial terms of time were introduced as independent variables. 152 Indicator variables were also considered in order to take into account the effect of block. This approach resulted in a rather complicated regression model. In order to obtain a simpler

154 polynomial equation, the effect of time was removed prior to applying MLR by subtracting 155 from each catch datum the average number of moths caught recorded in all traps at a given 156 day. Statistical analyses were performed using the Statgraphics plus 5.1 package (StatPoint 157 Technologies, Warrenton, VA, USA).

\section{Results}

\section{Pheromone emission rates}

161 The release profiles of $(E, Z)-7,9$-dodecadienyl acetate for the three types of dispensers 162 employed in this study are shown in Figure 1. The residual pheromone load [P $(\mu \mathrm{g})]$ was 163 fitted by polynomial regression in the case of PD1 and PD10 dispensers. The independent 164 variable was the number of days since dispensers were installed in the orchard [ $\mathrm{t}(\mathrm{time})]$. For 165 PD1 dispensers, a cubic equation was obtained (equation 1), resulting in a coefficient of 166 determination $\mathrm{R}^{2}=0.951$. No outliers were identified.

$$
\mathrm{P}_{\mathrm{PD} 1}=946.8-24.284 \cdot \mathrm{t}+0.311 \cdot \mathrm{t}^{2}-0.001488 \cdot \mathrm{t}^{3}
$$

A cubic equation was also obtained for PD10 dispensers. Data at $\mathrm{t}=0$ did not fit properly and they were disregarded, as well as three outliers, resulting in $\mathrm{R}^{2}=0.983$ (equation 2).

$$
\mathrm{P}_{\mathrm{PD} 10}=11605-281.25 \cdot \mathrm{t}+3.40 \cdot \mathrm{t}^{2}-0.01511 \cdot \mathrm{t}^{3}
$$

In the case of PD30 dispensers, the residual pheromone load follows an asymptotic trend 174 (Figure 1) and it was fitted by means of a non-linear exponential model (equation 3; $\mathrm{R}^{2}=$ 175 0.891).

$$
\mathrm{P}_{\mathrm{PD} 30}=19333+11148 \cdot \exp (-0.06367 \cdot \mathrm{t})
$$


The constant in equation 1 (946.8) coincides with the nominal load of PD1, which was

179

180

181

182

183

184

185

186

187

188

189

190

191

192

193

194

195

196

197

198

199

200

201

202

203

204

205

206

207 close to $1000 \mu \mathrm{g}$. Similarly, when $\mathrm{t}=0$ in equation 3 , P becomes 30481 , which is consistent with the initial load of PD30 dispensers. In the case of PD10, Figure 1 shows that the initial pheromone content was $10.8 \mathrm{mg}$, which is also close to the nominal value. The observed small differences are due to variability of the industrial manufacturing process.

The slope of the lines based on equations 1-3 is not constant (Figure 1), which implies that the daily emission rate of these pheromone dispensers decreases over time. This rate was estimated at day $t_{i}$ as the first derivative of the fitted equations, i.e., $d P / d t\left(t=t_{i}\right)$. Equations 4 , 5 , and 6 correspond to the first derivative of equations 1, 2, and 3, respectively. For example, 3PD1 traps inspected on 17 June correspond to traps collecting moths in the period of days 815 (i.e., $\mathrm{t}=8$ to $\mathrm{t}=15$ ). This trap contains three PD1 dispensers. Thus, the pheromone emission rate was estimated by applying equation 4 at $t=11.5$ (i.e., the midpoint of the 8-15 period), and the resulting value was multiplied by 3 . The release rate was assumed to be constant along the time interval. All estimated emission values are indicated in the Appendix.

$$
\begin{aligned}
& \frac{\mathrm{dP}_{\mathrm{PD} 1}}{\mathrm{dt}}=-24.284+0.622 \cdot \mathrm{t}-0.004464 \cdot \mathrm{t}^{2} \\
& \frac{\mathrm{dP}_{\mathrm{PD} 10}}{\mathrm{dt}}=-281.25+6.8 \cdot \mathrm{t}-0.04533 \cdot \mathrm{t}^{2} \\
& \frac{\mathrm{dP}_{\mathrm{PD} 30}}{\mathrm{dt}}=-709.8 \cdot \exp (-0.06367 \cdot \mathrm{t})
\end{aligned}
$$

\section{Field trial: Trap catches}

The period under study was characterized by the following average weather conditions (from June to August 2009): daily mean $\mathrm{T}=25.8^{\circ} \mathrm{C}, 59 \%$ r.h., and $0.8 \mathrm{~m} / \mathrm{s}$ wind speed. All traps showed population fluctuations of the pest though at different levels (Figure 2). First flight began around day 8 (10 June 2009), and the largest catches were recorded on day 22 (24 June). Second and third flights appeared on day 43 (15 July) and day 64 (5 August), respectively. These days correspond to the three flights of the moth cycle.

Most catch data recorded on 10 June and all data recorded on 18 August were null. Therefore, they were not further considered. Data of periods 43-52 and 52-57 were also rather low, $63 \%$ being zero. In order to overcome this lack of data variability, which is a problem if studying the effect of emission, both consecutive periods were merged as a single 43-57 interval (see the Appendix). 
It was observed that the numbers caught in blocks B and D tend to be higher than in blocks A and C. Actually, by means of one-way ANOVA it was found that the square root of the numbers caught is significantly different between blocks $\mathrm{A}$ and $\mathrm{C}$ vs. $\mathrm{B}$ and $\mathrm{D}(\mathrm{F}=8.60$; d.f.

$211=1,124 ; \mathrm{P}=0.004)$. This result could be explained by the clumped natural distribution of 212 grapevine moth populations (Coscollá et al., 1997; Ifoulis \& Savopoulou-Soultani, 2006).

213 In order to properly fit the square root of the numbers caught ( $\sqrt{\mathrm{Nc}})$ to time, block, and 214 emission, it would be necessary to use indicator variables for blocks and polynomial terms of 215 variable t, resulting in a rather complex equation. Instead, it seems preferable in this case to 216 eliminate the effect of block and time prior to applying MLR. For data collected at blocks A

217 and $\mathrm{C}$, we calculated the difference between $\sqrt{\mathrm{Nc}}$ and $\mathrm{ASB}_{\mathrm{AC}}$ (average square root of all 218 catch data recorded at blocks A and C). Similarly, for data collected at blocks B and D, $\sqrt{\mathrm{Nc}}-\mathrm{ASB}_{\mathrm{BD}}$ was calculated $\left(\mathrm{ASB}_{\mathrm{BD}}\right.$ as average square root of all catch data recorded at

220 blocks $\mathrm{B}$ and $\mathrm{D})$. The resulting variable $\sqrt{\mathrm{Nc}}-\mathrm{ASB}$ accounts for the variability not 221 explained by time or block that could be attributed to emission. Finally, a quadratic model 222 was fitted to relate $\sqrt{\mathrm{Nc}}-\mathrm{ASB}$ to the estimated emission rates (values available in the 223 supplementary material). Taking into account that emission values follow a positive skewed 224 distribution, SRE (square root of emission) was regarded as the independent variable 225 (equation 7). $\sqrt{\mathrm{Nc}}-\mathrm{ASB}=-0.784+0.129 \cdot \mathrm{SRE}-0.00322 \cdot \mathrm{SRE}^{2}$

The goodness-of-fit of equation 7 was low $\left(\mathrm{R}^{2}=0.142\right)$ but the regression coefficients were statistically significant $(\mathrm{P} \leq 0.0001)$. This result confirms the existence of a relative maximum of catches (Figure 3). Equation 7 was derived and equaled to zero, resulting in a square root of the optimum emission (SRE) of 19.9. Thus, the pheromone emission rate that maximizes attractant activity is: $19.9^{2}=396 \mu \mathrm{g}$ per day.

By means of a normal probability plot, it was checked that residuals of equation 7 (i.e., observed minus predicted values) followed approximately a normal distribution and no

236 influential points. Nonetheless, results are very similar if both data are discarded, and the 237 quadratic term is still clearly significant $(\mathrm{P}=0.0011)$. In order to study whether the effects of 238 block and time were properly eliminated with the procedure applied prior to MLR, residuals 239 of equation 7 were used as a dependent variable in a two-way ANOVA with factors block and 
240 time. The effect of both factors was not statistically significant $(\mathrm{F}=0.05 ;$ d.f. $=1,117 ; \mathrm{P}=0.83$

241 for block; $\mathrm{F}=0.20 ;$ d.f. $=6,117 ; \mathrm{P}=0.98$ for time) .

243 Discussion

244 Although it is demonstrated that the presence of minor compounds in L. botrana pheromone

245 formulations increases biological activity (Arn et al., 1988; El-Sayed et al., 1999), this work

246 employed (E,Z)-7,9-dodecadienyl acetate to determine the existence of an optimum sex

247 pheromone release rate, as it is the major pheromone component and the main compound

248 responsible for the attraction (Roelofs et al., 1973; Ideses et al., 1982; Witzgall et al., 2005).

249 The key factor to improve control methods based on pheromones as attractants (monitoring,

250 mass trapping, or 'attract and kill') is to know the optimum emission rate, because insect

251 response to the attractant could decrease below and above this optimal value (Jacobson \&

252 Beroza, 1964; Roelofs et al., 1977; Howse, 1998; Zhang \& Amalin, 2005). The inhibitory

253 effect of high pheromone doses has been reported for a number of lepidopterans (Roelofs \&

254 Cardé, 1974; Wyman, 1979; Millar et al., 1996). However, most of these works discuss insect

255 responses based on initial pheromone loads of the dispensers, which does not give a

256 conclusive idea about the actual release of pheromone, given that daily emission rates, and

257 therefore the amount of airborne pheromone, will depend on dispenser type and weather

258 conditions. The effect of pheromone dispenser type has been studied on maize stalkborer

259 catches: polyethylene vials loaded with $1 \mathrm{mg}$ pheromone caught significantly more moths

260 than rubber septa loaded with the same amount of ingredient (Critchley et al., 1997). Release

261 kinetics and dispenser field performance are key factors to develop efficient formulations for

262 dispensers, and must be known to establish the relationships between attractant power and

263 pheromone emission.

264 Some studies compare catches and pheromone doses for lepidopteran pests, resulting in a

265 variety of relationships. Leonhardt et al. (1990) tested cotton wick dispensers for gypsy moth

266 [Lymantria dispar (L.)] and proposed an optimal reference release rate of $11.3 \mu \mathrm{g}$ per day, but

267 plastic laminate dispensers could remain highly attractive by emitting at least $0.72 \mu \mathrm{g}$ per day.

268 Kehat and coworkers (1994) found increasing catches of codling moth [Cydia pomonella (L.)]

269 males with increasing pheromone doses, within the range of 0.1 to $100 \mu \mathrm{g}$, but rubber septa

270 loaded with $5000 \mu \mathrm{g}$ were significantly less attractive than 100 or $1000 \mu \mathrm{g}$ dispensers.

271 Similar behavior was observed for rice leaffolder moth, Cnaphalocrocis medicinalis (Guenée)

272 (Kawazu et al., 2004). Vacas et al. (2009) found decreasing catches of Chilo suppressalis

273 (Walker) below and above an optimal release rate of $34 \mu \mathrm{g}$ per day. And Jactel and coworkers 
274 (2006) found an asymptotic increase response of catches of pine processionary moth

275 (Thaumetopoea pytiocampa Denis \& Schiffermüller) according to increasing doses of its 276 pheromone from 0.5 to $20 \mathrm{mg}$, with $95 \%$ of maximum catch obtained with the $10-\mathrm{mg}$ dosage.

277 This asymptotic pattern has also been observed in other Lepidoptera species (Evenden et al., 278 1995; Knutson et al., 1998; Rao \& Subbaratnam, 1998).

279 Many papers have studied the effect of dispenser type and pheromone load for a variety of 280 insect families (Mason et al., 1990; Cork et al., 2001; Franklin \& Gregoir, 2001; Branco et al., 281 2004; Kovanci et al., 2006). However, only few studies determined the optimal release rate of 282 attractants (de Groot \& DeBarr, 1998; Cross et al., 2006; Vacas et al., 2009). As mentioned 283 above, catches do not always increase with increasing pheromone doses. Usually, catches 284 increase up to an optimal dose. For higher values, trap catches could remain constant or 285 decrease due to a repellent effect. An optimum pheromone load for L. botrana monitoring 286 dispensers has been suggested by Roehrich et al. (1983), who found that pheromone loads 287 between $1 \mu \mathrm{g}$ and $10 \mathrm{mg}$ allowed the detection of moths. Anshelevich et al. (1994) reported 288 that $L$. botrana males responded positively to sticky traps baited with rubber septa loaded 289 with increasing doses from $0.1 \mu \mathrm{g}$ to $0.1 \mathrm{mg}$ pheromone, but loads of $1-10 \mathrm{mg}$ caught 290 significantly fewer moths. However, emission rates were only measured for 1-mg septa, so 291 trap catches were not correlated with emission values and optimal release rates were not 292 proposed. These studies only reported optimum pheromone loads, but the values cannot be 293 adopted as a reference, because it has been demonstrated that similar initial loads in different 294 dispenser types may result in different release rates (Leonhard et al., 1990; Dominguez-Ruiz 295 et al., 2008). Instead, the most suitable reference value to optimize the dispenser performance 296 would be the optimum daily release rate, as this is the actual variable responsible for the 297 airborne pheromone acting in insect attraction. Determination of this value could be of 298 interest to develop more effective dispensers, so that they are able to emit pheromone at the 299 optimum level.

300 This trial employed different mesoporous dispensers, with pheromone loads ranging from 3011 to $30 \mathrm{mg}$, to obtain the optimum daily emission rate. Release profiles of PD1 and PD10 302 were fitted to cubic equations, implying that their emission rates were not constant. However, 303 their life span was at least 100 days (Figure 1) and their residual pheromone loads, at the end 304 of the period under study, were $15 \%$ of the initial load for PD1 (equation $1, t=100$ ) and $22 \%$ 305 for PD10 (equation 2, $\mathrm{t}=100$ ). On the other hand, the release profile of PD30 was fitted to a 306 model (equation 3) with an asymptote at $19333 \mu \mathrm{g}$, which means that about $63 \%$ of its initial 307 load was not released, and more than half of the pheromone load was wasted. This is not a 
308 suitable feature for an ideal dispenser, as pheromone accounts for $95 \%$ of the cost of the 309 dispensers and the use of pheromone must be optimized. Thus, PD30 would need changes in 310 its formulation or design to gain efficiency. However, the life span of PD30 dispensers was enough for the purpose of this work, which was to monitor the main flights of L. botrana in 312 the study area.

313 This study concludes that releasing (E,Z)-7,9-dodecadienyl acetate, the major pheromone 314 component of the European grapevine moth, at a rate of about $400 \mu \mathrm{g}$ per day would 315 maximize moth attraction under West-Mediterranean weather conditions. Although

316 significant, the scope of the statistical relationship found between catches and emission could 317 be somewhat limited. It should be stressed that the field trial was carried out only in one 318 location and the optimum release rate could be affected by environmental conditions, 319 specially the wind, in so far as pheromone plume is modified (Murlis et al., 1992).

320 Nevertheless, this value could be generalized to catches of L. botrana under the average 321 climatic conditions required for its development in temperate Mediterranean areas. An 322 optimum release value is, in any case, a key datum for dispenser manufacturers, as well as a 323 tool to improve L. botrana management methods based on pheromones.

\section{Acknowledgements}

326 We want to thank Bodegas J. Belda (Fontanars dels Alforins, Valencia, Spain) for providing 327 test orchards and C. Colás for his invaluable field assistance.

\section{References}

330 Anshelevich L, Kehat M, Dunkelblum E \& Greenberg S (1994) Sex pheromone traps for monitoring the European vine moth, Lobesia botrana - Effect of dispenser type, pheromone dose, field aging of dispenser, and type of trap on male captures. Phytoparasitica 22: 281-290.

Arn H, Rauscher S, Guerin P \& Buser HR (1988) Sex pheromone blends of three tortricid pests in European vineyards. Agriculture, Ecosystems \& Environment 21: 111-117.

Bradley SJ, Suckling DM, Mcnaughton KG, Wearing CH \& Karg G (1995) A temperaturedependent model for predicting release rates of pheromone from a polyethylene tubing dispenser. Journal of Chemical Ecology 21: 745-760.

Branco M, Jactel H, Silva EB, Binazzi A \& Mendel Z (2004) Effect of trap design, trap size and pheromone dose on male capture of two pine bast scales species (Hemiptera: Matsucoccidae): Implications for monitoring and mass trapping. Agricultural and Forest 
Entomology 6: 233-239.

343 Coscollá R (1997) Ciclo biológico. La Polilla del Racimo de la Vid (Lobesia botrana Den. y Schiff.) (ed. by Generalitat Valenciana - Conselleria de Agricultura, Pesca y Alimentación), pp. 79-108. CAPA, Valencia, Spain.

Cork A, Alam SN, Das A, Das CS, Ghosh GC et al. (2001) Female sex pheromone of brinjal fruit and shoot borer, Leucinodes orbonalis blend optimization. Journal of Chemical

Corma A, Muñoz-Pallares J \& Primo-Yufera E (1999) Production of semiochemical emitters having a controlled emission speed which are based on inorganic molecular sieves. World Patent WO9944420.

Corma A, Muñoz-Pallares J \& Primo-Yufera E (2000) Emitter of semiochemical substances supported on a sepiolite, preparation process and applications. World Patent WO0002448.

Critchley BR, Hall DR, Farman DI, McVeigh LJ, Mulaa MAOA \& Kalama P (1997) Monitoring and mating disruption of the maize stalkborer, Busseola fusca, in Kenya with

Cross JV, Hesketh H, Jay CN, Hall DR, Innocenzi PJ et al. (2006) Exploiting the aggregation pheromone of strawberry blossom weevil Anthonomus rubi Herbst (Coleoptera: Curculionidae): Part 1. Development of lure and trap. Crop Protection 25: 144-154.

de Groot P \& DeBarr GL (1998) Factors affecting capture of the white pine cone beetle, Conophthorus coniperda (Schwarz) (Col., Scolytidae) in pheromone traps. Journal of

Dominguez-Ruiz J, Sanchis J, Navarro-Llopis V \& Primo J (2008) A new long-life trimedlure dispenser for Mediterranean fruit fly. Journal of Economic Entomology 101: 1325-1330.

El-Sayed A, Gödde J, Witzgall P \& Arn H (1999) Characterization of pheromone blend for Applied Entomology 122: 281-286. grapevine moth, Lobesia botrana, by using flight track recording. Journal of Chemical Ecology 25: 389-399.

Evenden ML, Borden JH, Van Sickle GA \& Gries G (1995) Development of a pheromonebased monitoring system for western hemlock looper (Lepidoptera: Geometridae): Effect of pheromone dose, lure age, and trap type. Environmental Entomology 24: 923-932.

Franklin AJ \& Gregoir JC (2001) Dose-dependent response and preliminary observations on attraction range of Ips typographus to pheromones at low release rates. Journal of Chemical Ecology 27: 2425-2435.

Howse PE (1998) Pheromones and behavior. Insect Pheromones and their Use in Pest 
Management (ed. by PE Howse, I Stevens \& O Jones), pp. 1-130. Chapman \& Hall, London, UK.

Ideses R, Klug JT, Shani A, Gothilf S \& Gurevitz E (1982) Sex pheromone of the European grapevine moth, Lobesia bitrana Schiff. (Lepidoptera: Tortricidae): Synthesis and effect of isomeric purity on biological activity. Journal of Chemical Ecology 8: 195-200.

Ifoulis AA \& Savopoulou-Soultani M (2006) Use of geostatistical analysis to characterize the spatial distribution of Lobesia botrana (Lepidoptera: Tortricidae) larvae in northern Greece. Environmental Entomology 35: 497-506.

Jacobson M \& Beroza M (1964) Insect attractants. Scientific American 211: 20-27.

Jactel H, Menassieu P, Vétillard F, Barthélémy B, Piou D et al. (2006) Population monitoring of the pine processionary moth (Lepidoptera: Thaumotopoeidae) with pheromone-baited traps. Forest Ecology and Management 235: 96-106.

Jutsum AR \& Gordon RFS (1989) Pheromones: Importance to insects and role in pest management. Insect Pheromones in Plant Protection (ed. by AR Jutsum \& RFS Gordon), pp. 1-13. John Wiley \& Sons, Surrey, UK.

Kawazu K, Kamimuro T, Kamiwada H, Nagata K, Matsunaga T et al. (2004) Effective pheromone lures for monitoring the rice leaffolder moth, Cnaphalocrocis medinalis (Lepidoptera: Crambidae). Crop Protection 23: 589-593.

Kehat M, Anshelevich L, Dunkelblum E, Fraishtat P \& Greenberg S (1994) Sex pheromone

Knutson AE, Marvin I, Harris K \& Millar JG (1998) Effects of pheromone dose, lure age, and trap design on capture of male pecan nut casebearer (Lepidoptera: Pyralidae) in pheromone-baited traps. Journal of Economic Entomology 91: 715-722.

Kovanci O, Schal C, Walgenbach F \& Kennedy G (2006) Effects of pheromone loading, dispenser age, and trap height on pheromone trap catches of the oriental fruit moth in apple orchards. Phytoparasitica 34: 252-260.

Leonhardt BA, Cunningham RT, Rice RE, Harte EM \& Hendrichs J (1989) Design, effectiveness and performance criteria of dispenser formulations of trimedlure, and attractant of the Mediterranean fruit fly (Diptera: Tephritidae). Journal of Economic Entomology 82: 860-867.

Leonhardt BA, Mastro VC, Paszek EC, Schwalbe CP \& Devilbiss ED (1990) Dependence of gypsy-moth (Lepidoptera: Lymantriidae) capture on pheromone release rate from 
laminate and other dispensers. Journal of Economic Entomology 83: 1977-1981.

Mason LJ, Jansson RK \& Heath RR (1990) Sampling range of male sweetpotato weevils (Cylas fornicarius elegantulus) (Summers) (Coleoptera: Curculionidae) to pheromone traps: Influence of pheromone dosage and lure age. Journal of Chemical Ecology 16: 2493-2502.

Millar JG, Knutson AE, McElfresh JS, Gries R, Gries G et al. (1996) Sex attractant pheromone of the pecan nut casebearer (Lepidoptera: Pyralidae). Bioorganic \& Medicinal Chemistry 4: 331-339.

Murlis J, Elkinton JA \& Cardé RT (1992) Odor plumes and how insects use them. Annual Review of Entomology 37: 505-532.

Rao DVS \& Subbaratnam GV (1998) Sex pheromone monitoring of the ragi cutworm, Spodoptera exigua (Hubner) in onion: Effect of trap height and pheromone dose on moth catch. Pest Management and Economic Zoology 6: 21-25.

Roehrich R, Carles JP, Dreuilhe A \& Vonderheyden F (1983) Captures de Lobesia botrana Den. \& Schiff. (Lepidoptera: Tortricidae) au piège sexuel en relation avec la dose en phéromone du diffuseur. Agronomie 3: 925-930.

Roelofs WL, Kochansky S, Darde R, Arn H \& Rauscher S (1973) Sex attractant of the grape vine moth Lobesia botrana. Mitteilungen der Schweizerische Entomologische Gesellschaft 46: 71-73.

Roelofs WL \& Cardé RT (1974) Oriental fruit moth and lesser appleworm attractant mixtures redefined. Environmental Entomology 3: 586-588.

Roelofs WL, Gieselmann MJ, Carde AM, Tashiro H, Moreno DS et al. (1977) Sex pheromone of California red scale, Aonidiella aurantii. Nature 267: 698-699.

Vacas S, Alfaro C, Navarro-Llopis V, Zarzo M \& Primo J (2009) Study on the optimum pheromone release rate for attraction of Chilo suppressalis (Lepidoptera: Pyralidae). Journal of Economic Entomology 102: 1094-1100.

Witzgall P, Tasin M, Buser H, Wegner-Kib G, Marco Mancebon VS et al. (2005) New pheromone components of the grapevine moth Lobesia botrana. Journal of Chemical Ecology 31: 2923-2932.

Witzgall P, Kirsch P \& Cork A (2010) Sex pheromones and their impact on pest management. Journal of Chemical Ecology 36: 80-100.

Wyman JA (1979) Effect of trap design and sex attractant release rates on tomato pinworm catches. Journal of Economic Entomology 72: 865-868.

Zhang A \& Amalin D (2005) Sex pheromone of the female pink hibiscus mealybug, 

evaluation. Environmental Entomology 34: 264-270.

446

447 Figure legends

448 Figure 1 Release profiles of (E,Z)-7,9-dodecadienyl acetate, the major Lobesia botrana 449 pheromone component, from the three kinds of dispensers tested. Fitted curves describe the 450 pheromone content of the dispenser $[\mathrm{P}(\mu \mathrm{g})]$ vs. time $(\mathrm{t}=$ number of days in orchard $)$. For 451 equation 2 , points indicated as diamonds $(\diamond)$ were not taken into account to obtain the 452 regression equation.

453

454 Figure 2 Average number of moths caught per trap and week (MTW) for each of five types of 455 baited trap, with t the day of inspection (day 0 corresponds to 2 June 2009 at which most traps 456 were installed). Baited traps were delta traps and dispensers were not replaced.

457

458 Figure 3 Scatter plot and fitted regression model (equation 7) of $\sqrt{\mathrm{Nc}}-\mathrm{ASB}$ vs. SRE

459 (square root of emission). The dependent variable is the square root of numbers caught minus 460 the average square root of catches collected at blocks A and C, or B and D (ASB). 
462 Appendix Pheromone emission rates and numbers caught of Lobesia botrana in traps baited

463 with pheromone dispensers

\begin{tabular}{|c|c|c|c|c|c|c|c|c|c|c|}
\hline \multirow{2}{*}{$\begin{array}{l}\text { Day } \\
\text { period }^{1}\end{array}$} & \multirow[b]{2}{*}{ Date $^{2}$} & \multirow{2}{*}{$\begin{array}{l}\text { Trap } \\
\text { code }^{3}\end{array}$} & \multicolumn{4}{|c|}{ Catches at each block $^{5}$} & \multicolumn{2}{|c|}{$\mathrm{ASB}^{6}$} & \multicolumn{2}{|l|}{ Emission } \\
\hline & & & $\mathrm{A}$ & $\mathrm{C}$ & $\mathrm{B}$ & $\mathrm{D}$ & $\mathrm{A}-\mathrm{C}$ & $\overline{B-D}$ & $\left(\mu \mathrm{g} \mathrm{day}^{-1}\right)$ & proced. $^{\top}$ \\
\hline \multirow[t]{4}{*}{$0-8$} & 10 June & PD1 & 2 & 0 & - & 1 & 0.18 & 0.29 & & \\
\hline & & 3PD1 & 0 & 0 & 1 & 0 & 0.18 & 0.29 & & \\
\hline & & PD10 & 0 & 0 & 0 & 0 & 0.18 & 0.29 & & \\
\hline & & 3PD10 & 0 & 0 & 0 & 0 & 0.18 & 0.29 & & \\
\hline \multirow[t]{4}{*}{$8-15$} & 17 June & PD1 & 1 & 0 & 5 & 4 & 2.54 & 3.90 & 18 & $(4)_{t=11.5}$ \\
\hline & & 3PD1 & 4 & 5 & 10 & 13 & 2.54 & 3.90 & 53 & $3 \cdot(4)_{t=11.5}$ \\
\hline & & PD10 & 15 & 8 & 16 & 16 & 2.54 & 3.90 & 209 & $(5)_{t=11.5}$ \\
\hline & & 3PD10 & 15 & 20 & 37 & 37 & 2.54 & 3.90 & 627 & $3 \cdot(5)_{t=11.5}$ \\
\hline \multirow[t]{4}{*}{$15-22$} & 24 June & PD1 & 1 & 4 & 12 & 13 & 2.87 & 5.20 & 14 & $\overline{(4)_{t=18.5}}$ \\
\hline & & 3PD1 & 8 & 5 & 25 & 27 & 2.87 & 5.20 & 43 & $3 \cdot(4)_{t=18.5}$ \\
\hline & & PD10 & 23 & 6 & 40 & 18 & 2.87 & 5.20 & 171 & $(5)_{t=18.5}$ \\
\hline & & 3PD10 & 10 & 20 & 50 & 45 & 2.87 & 5.20 & 513 & $3 \cdot(5)_{t=18.5}$ \\
\hline \multirow[t]{5}{*}{$22-29$} & 1 July & PD1 & 8 & 4 & 19 & 12 & 2.44 & 4.18 & 11 & $\overline{(4)_{t}=25.5}$ \\
\hline & & 3PD1 & 3 & 4 & 21 & 25 & 2.44 & 4.18 & 34 & $3 \cdot(4)_{t=25.5}$ \\
\hline & & PD10 & 7 & 6 & 33 & 17 & 2.44 & 4.18 & 137 & $(5)_{t=25.5}$ \\
\hline & & 3PD10 & 13 & 3 & 20 & 27 & 2.44 & 4.18 & 412 & $3 \cdot(5)_{t=25.5}$ \\
\hline & & $3 \mathrm{PD} 30^{4}$ & - & 9 & 10 & 3 & 2.44 & 4.18 & 1704 & $3 \cdot(6)_{t=3.5}$ \\
\hline \multirow[t]{5}{*}{$29-36$} & 8 July & PD1 & 1 & 2 & 0 & 4 & 0.67 & 1.28 & 9 & $(4)_{t=32.5}$ \\
\hline & & 3PD1 & 0 & 2 & 6 & 2 & 0.67 & 1.28 & 26 & $3 \cdot(4)_{t=32.5}$ \\
\hline & & PD10 & 0 & 2 & 0 & 1 & 0.67 & 1.28 & 108 & $(5)_{t=32.5}$ \\
\hline & & 3PD10 & 2 & 0 & 5 & 1 & 0.67 & 1.28 & 324 & $3 \cdot(5)_{t=32.5}$ \\
\hline & & 3PD30 & 0 & 0 & - & 2 & 0.67 & 1.28 & 1091 & $3 \cdot(6)_{t=10.5}$ \\
\hline \multirow[t]{5}{*}{$36-43$} & 15 July & PD1 & 0 & 5 & 1 & 6 & 2.37 & 1.58 & 7 & $\overline{(4)_{t=39.5}}$ \\
\hline & & 3PD1 & 6 & 11 & 7 & 1 & 2.37 & 1.58 & 20 & $3 \cdot(4)_{t=39.5}$ \\
\hline & & PD10 & 1 & 16 & 3 & 3 & 2.37 & 1.58 & 83 & $(5)_{t=39.5}$ \\
\hline & & 3PD10 & 7 & 21 & - & 7 & 2.37 & 1.58 & 250 & $3 \cdot(5)_{t=39.5}$ \\
\hline & & 3PD30 & 6 & 1 & 1 & 0 & 2.37 & 1.58 & 699 & $3 \cdot(6)_{t=17.5}$ \\
\hline \multirow[t]{5}{*}{$43-57$} & 29 July & PD1 & 0 & 0 & 2 & 0 & 0.48 & 1.00 & 4 & $\overline{(4)_{t=50}}$ \\
\hline & & 3PD1 & 0 & 0 & 6 & 1 & 0.48 & 1.00 & 13 & $3 \cdot(4)_{t=50}$ \\
\hline & & PD10 & 2 & 1 & 0 & 1 & 0.48 & 1.00 & 55 & $(5)_{t=50}$ \\
\hline & & 3PD10 & 0 & 1 & 0 & 3 & 0.48 & 1.00 & 164 & $3 \cdot(5)_{\mathrm{t}=50}$ \\
\hline & & 3PD30 & 0 & 2 & 2 & 1 & 0.48 & 1.00 & 358 & $3 \cdot(6)_{t=28}$ \\
\hline \multirow[t]{3}{*}{$\begin{array}{l}57-64 \\
\end{array}$} & 5 Aug & PD1 & 1 & 5 & 5 & 0 & 1.78 & 2.03 & 3 & $\overline{(4)_{t=60.5}}$ \\
\hline & & 3PD1 & - & - & 13 & 6 & 1.78 & 2.03 & 9 & $3 \cdot(4)_{t=60.5}$ \\
\hline & & PD10 & 4 & 1 & 5 & 2 & 1.78 & 2.03 & 36 & $(5)_{t=60.5}$ \\
\hline
\end{tabular}




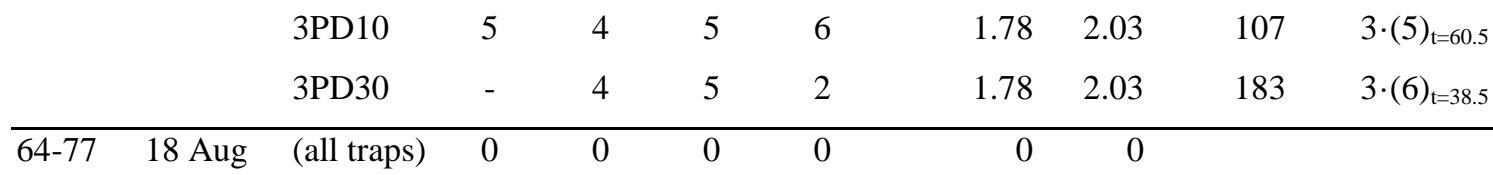

$464{ }^{1}$ Day 0 corresponds to 2 June 2009, when all traps (except 3PD30) were installed.

$465{ }^{2}$ Date at which traps were inspected for counting.

$466{ }^{3}$ Initial pheromone load: $1 \mathrm{mg}$ (PD1), $3 \mathrm{mg}$ (3PD1), $10 \mathrm{mg}$ (PD10), $30 \mathrm{mg}$ (3PD10), and $90 \mathrm{mg}$ 467 (3PD30).

$468{ }^{4}$ Traps 3PD30 were set up on 24 June.

$469{ }^{5}$ No. moths caught.. Missing data are marked as '-'.

$470{ }^{6}$ Average of the square root of catches recorded at blocks A and C, or B and D.

$471{ }^{7}$ Procedure used to calculate emission values (see text for a detailed explanation). The equation used is 472 indicated within parentheses, and $\mathrm{t}$ is the median number of days in orchard.

473

474 
$475 \quad$ Fig1

476
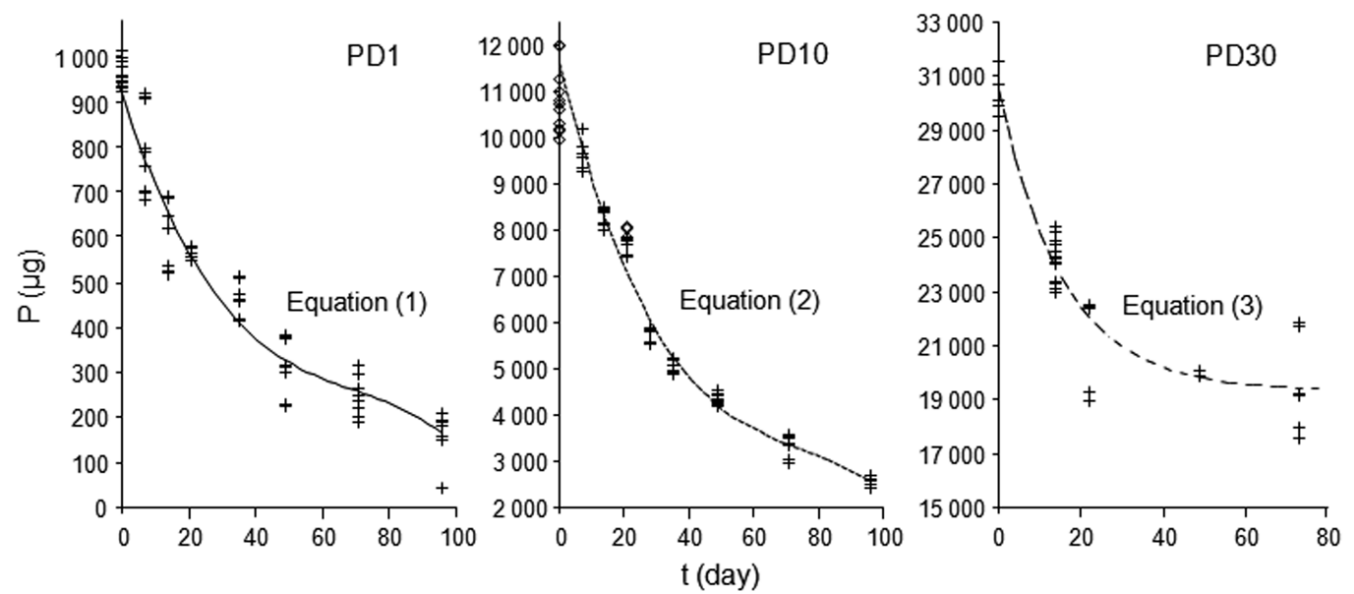

477
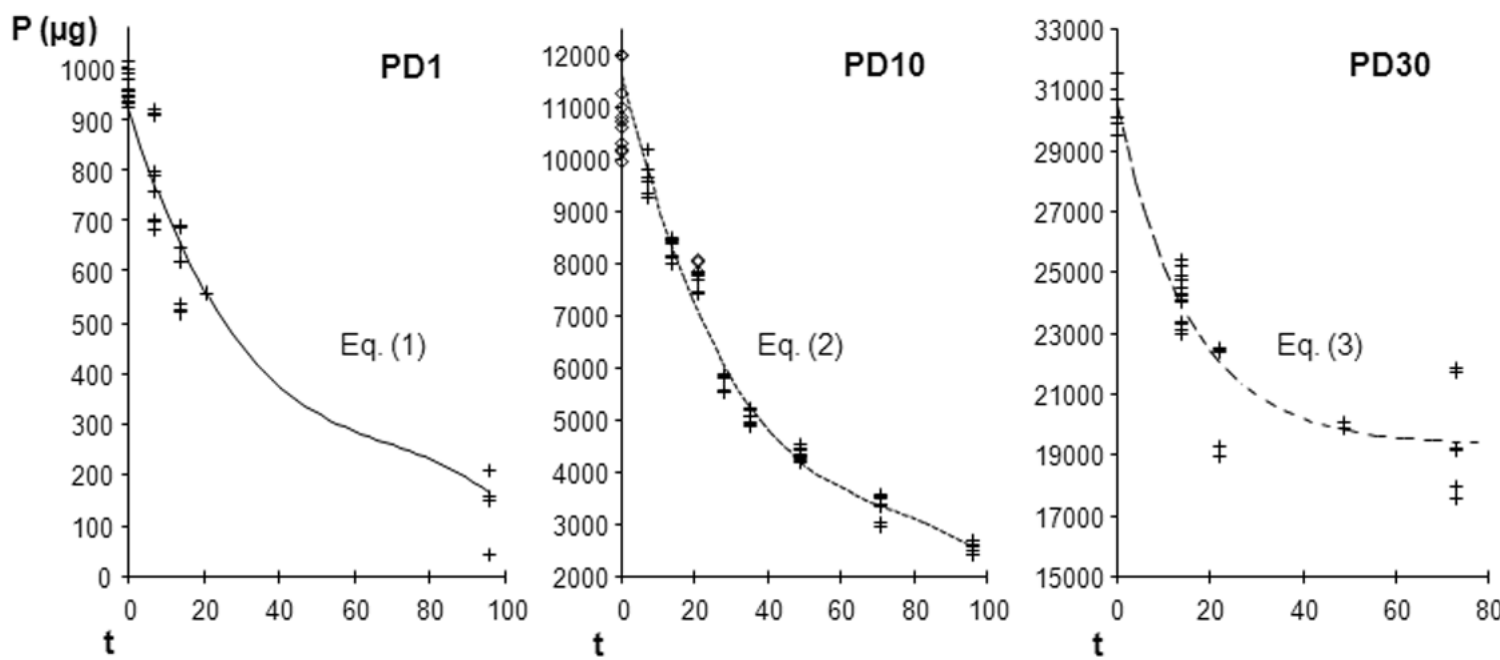

479

480 
Fig2

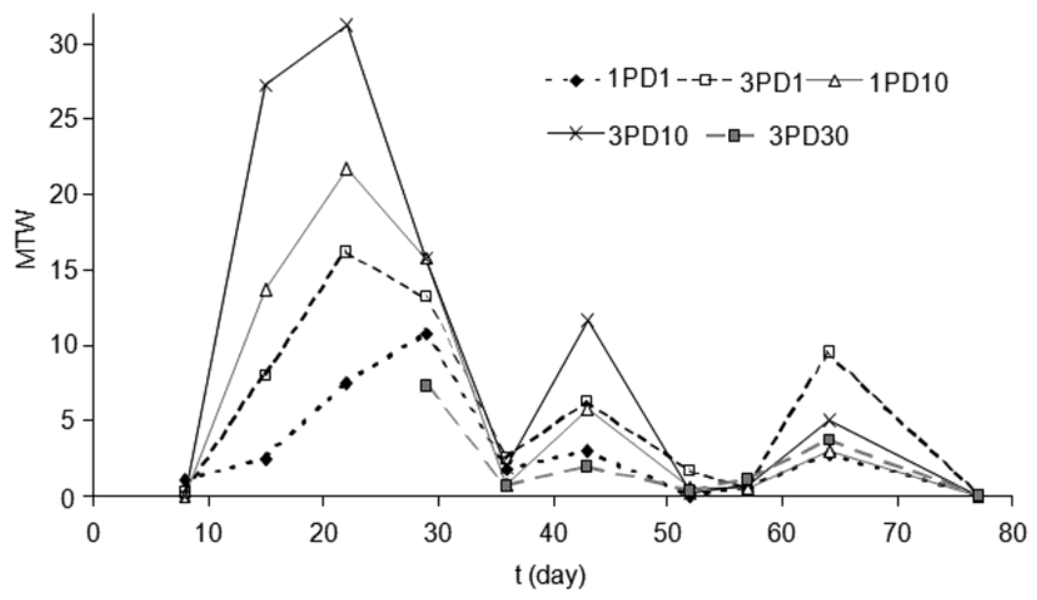

482

483

484 
485

Fig3

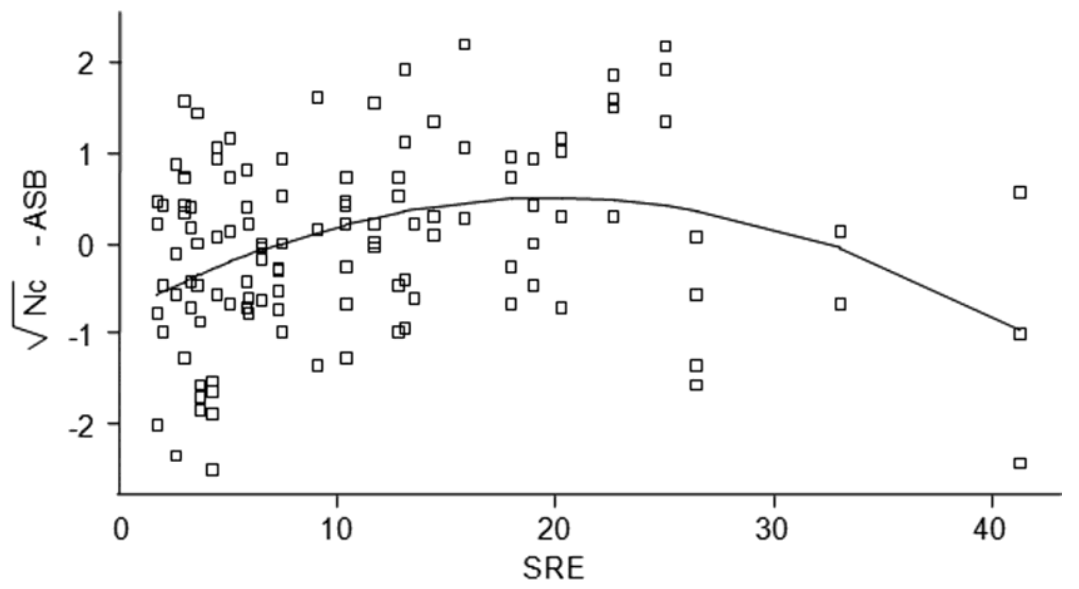

486

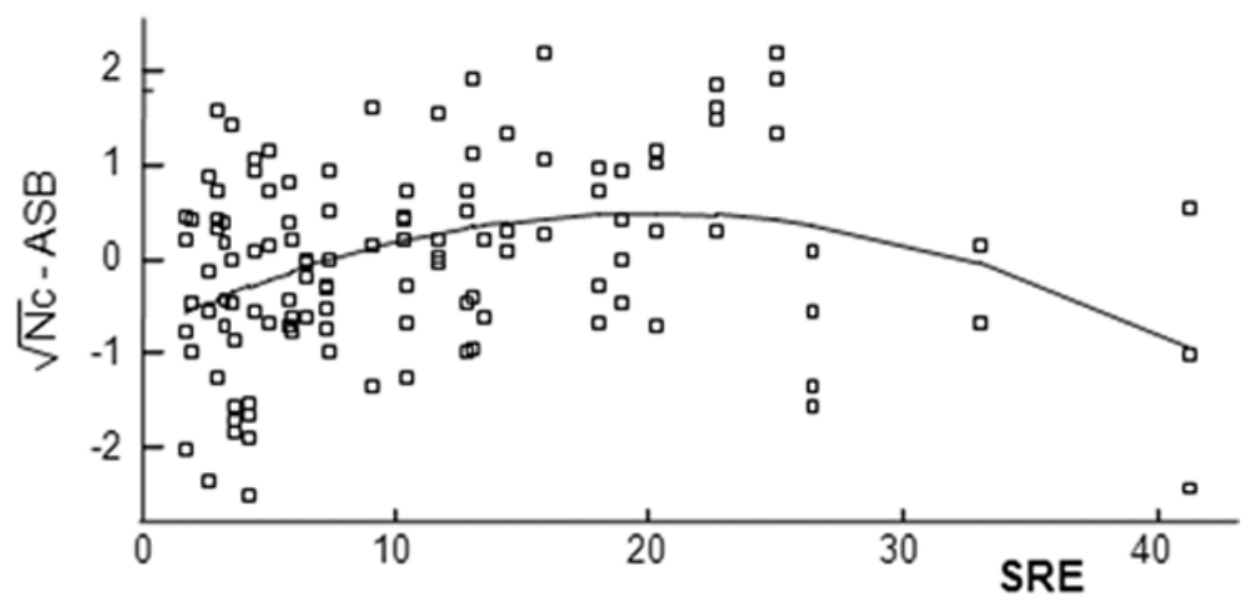

487

488 